\title{
Mineração de areia e meio ambiente: é possível harmonizar?
}

\author{
OPERATING SAND AND ENVIRONMENT: CAN \\ HARMONISING? \\ * Eriton Geraldo Vieira \\ ** Elcio Nacur Rezende
}

** Mestrando em Direito Ambiental e Desenvolvimento Sustentável pela Escola Superior Dom Helder Câmara. Bolsista pela FAPEMIG. Especialista em Direito Público pelo Instituto de Educação Continuada da Pontifícia Universidade Católica de Minas Gerais. Pós graduando em Direito Civil e Processo Civil pela Escola Superior Dom Helder Câmara. Email: eritonbh@yahoo. com.br

* Coordenador e Professor do Curso de Mestrado em Direito Ambiental e Desenvolvimento Sustentável da Escola Superior Dom Helder Câmara. Mestre e Doutor em Direito pela Pontifícia Universidade Católica de Minas Gerais. Especialista em Direito Público pela Universidade Gama Filho. Coordenador e Professor do Curso de Mestrado em Direito Ambiental e Desenvolvimento Sustentável da Escola Superior Dom Helder Câmara. E-mail: elcionacur@yahoo.com.br>
Resumo: A mineração é considerada um dos setores básicos da economia do Brasil. A atividade minerária fornece matéria prima base para a indústria, sendo que vários produtos desde os mais simples aos mais complexos têm origem mineral. Os produtos mais minerados no Brasil, em volume, são a areia e a pedra britada. As atividades de extração de areia são de grande importância para o desenvolvimento social, mas igualmente responsáveis por impactos ambientais negativos, alguns inclusive irreversíveis. Em virtude da rigidez locacional, o minerador de areia está obrigado a minerar onde há a ocorrência do mineral que constantemente localiza-se próximo a fundo de vales e aos rios, coincidindo muitas vezes com as matas ciliares, consideradas Áreas de Preservação Permanente (APP). Neste contexto, objetiva-se demonstrar através de uma abordagem dialética, procedimentalmente desenvolvida através de pesquisa bibliográfica e documental, a possibilidade de conciliar a exploração do minério de areia em Áreas de Preservação Permanente. Sendo assim, serão analisados os preceitos estabelecidos na Lei n. 12.651/12 (nova lei florestal) bem como serão evidenciados os impactos socioeconômicos e ambientais oriundos da atividade minerária que terão que ser observados para a concretização da função socioambiental da propriedade. A pesquisa teve como suporte o método qualitativo e na sua construção utilizou-se da técnica da revisão bibliográficodocumental.

Palavras-Chave: Áreas de preservação permanente. Função socioambiental da propriedade. Impactos socioeconômicos e ambientais. Mineração de areia.

Abstract: Mining is considered one of the basic sectors of Brazil's economy. The mining activity provides basic raw material for industry, and several products from the simplest to the most complex have mineral origin. Most products mined in Brazil, by volume, are sand and crushed stone. The sand extraction activities are of great importance for social development, but equally responsible for negative environmental impacts, sometimes irreversible. Due to the 
location's rigidity, the sand miner is forced to mine where there is mineral occurrence, which constantly is near the bottom of valleys and rivers, often coinciding with the riparian forests, which are considered to be permanently protected areas (APP). In this context, objective is to demonstrate through a dialectical approach, procedurally developed through literature the possibility of conciliating the exploration of ore sand in permanently protected areas. Thus, will be analyzed the rules established in the Law 12.651/12 (New forest law), as well as will be demonstrated the socioeconomic and environmental impacts of mining activities which have to be observed to achieve the environmental function of property. The research was supported by the qualitative method and its construction we used the technique of bibliographical and documentary review.

Keyword: Sand mining. Permanently protected areas. Aocioeconomic and environmental impacts. Environmental function of property. 


\section{INTRODUÇÃO}

Os contornos de questões relacionadas à mineração e ao meio ambiente ganharam espaço no início do século XXI e têm-se constituído em pauta importantíssima em cenários nacionais e internacionais em que são debatidos temas relacionados ao Desenvolvimento Sustentável.

Nesse sentido, o presente artigo levanta uma importante discussão na seara das diversas áreas científicas, pois traça, vários aspectos referentes à exploração do minério de areia em Áreas de Preservação Permanente (APP) e seus impactos socioeconômicos e ambientais no Brasil.

Inicialmente, serão demonstrados aspectos referentes à mineração no Brasil e à extração de minério de areia, revelando-se esta primeira seção, essencial para o desenvolvimento do trabalho.

O Brasil é um dos países mais ricos em recursos ambientais naturais do planeta e, neste contexto, os minerais possuem uma posição de destaque, entretanto, geralmente, a produção do mineral de areia ocorre em várzeas e leitos de rios, junto a matas ciliares, consideradas Áreas de Preservação Permanente, tornando um empecilho à atividade minerária, uma vez que são consideradas "áreas protegidas".

Nesse sentido, posteriormente, serão analisadas algumas características referentes às Áreas de Preservação Permanente, bem como a possibilidade de intervenção ou supressão de vegetação e a concretização da função socioambiental da propriedade.

Quando se fala em função socioambiental da propriedade, na verdade se diz que ao proprietário de um bem se impõe o dever de exercer o seu direito de propriedade não apenas em seu próprio interesse, mas em benefício da coletividade. Dessa forma, há uma obrigação legal de manterem-se as Áreas de Preservação Permanente com vegetação e os proprietários devem se sujeitar a ela.

Por fim, serão evidenciados vários aspectos relacionados à mineração de areia em Áreas de Preservação Permanente, com o objetivo de se verificar a adequação da atividade de extração de areia aos requisitos legais e aos aspectos ambientais, e levantar as principais alterações ambientais associadas à atividade sobre as Áreas de Preservação Permanente bem como demonstrar estudos de casos realizados no Rio Tibagi, em Ponta Grossa/PR e em três pontos de extração no município de Campestre de Goiás/GO, para análise da 
importância e dos impactos ambientais causados pela extração da mineração de areia nas referidas regiões.

Para obtenção dos objetivos colimados, a metodologia adotada no artigo baseou-se no método dialético, com uma abordagem qualitativa, através de pesquisa exploratória, que proporcionou o aprofundamento do tema.

\section{A MINERAÇÃO NO BRASIL}

O Brasil é um dos países mais ricos em recursos ambientais naturais do planeta e, nesse contexto, os minerais possuem uma posição de destaque. A mineração no Brasil "é acompanhada pelo processo de ocupação territorial, tendo como principal intuito a exploração das riquezas minerais" (CLEMENTE, LEITE, PEREIRA, 2013, p. 85).

Segundo Farias (2002, p. 3), a própria história do Brasil, “tem íntima ligação com a busca e aproveitamento dos recursos minerais, que sempre contribuiu com importantes insumos da economia nacional, fazendo parte da ocupação territorial e da história nacional".

Devido à rigidez locacional, o minerador tem o ônus de se ocupar e explorar as jazidas onde há a ocorrência de recursos minerais. Melo (2008, p. 27) observa que, "desde os primórdios, a mineração, em suas diversas modalidades, de diamantes a areia, de minério de ferro, do petróleo a água, sempre alavancou todo um processo de desenvolvimento socioeconômico, quer direta, quer indiretamente".

Em termos gerais, a mineração pode ser considerada uma atividade de extração de minerais que possua valor econômico. A atividade fornece matéria prima base para a indústria, sendo que vários produtos, desde os mais simples aos mais complexos, têm origem mineral. Para Lins (2005, p.11):

Qualquer atividade agrícola ou industrial, no campo da metalurgia, da indústria química, da construção civil ou do cultivo de terra, utiliza os minerais e os seus derivados. Os fertilizantes, os metais e suas ligas, o cimento, a cerâmica, o vidro, são todos produzidos a partir de matérias primas minerais. É cada vez maior a influência dos minerais sobre a vida e o desenvolvimento de um país. Com o aumento das populações, cada dia se necessita de maior quantidade de minerais para atender às crescentes necessidades.

Do mesmo modo, Costa e Amorim (2011, p. 43) entendem que: 
Inimaginável seria a vida sem minerais, metais e compostos metálicos, essenciais à vida das plantas, dos animais e dos seres humanos. Óbvio, dessa forma, que o desenvolvimento de um país com vocação mineral está essencialmente ligado ao desenvolvimento desta atividade, não só pelo enfoque da construção civil (areia, rochas ornamentais, cascalho, brita, ferro, etc.) como pelo lado do combate à fome (fosfato e potássio, essenciais à produção de fertilizantes) e do desenvolvimento industrial.

O perfil do setor mineral brasileiro é composto por $95 \%$ de pequenas e médias minerações. Estima-se que "existam mais de 8.000 mineradoras em operação no Brasil, que exploram 55 tipologias minerais"(MANCIN, 2012).

Segundo a Revista Minérios \& Minerales (1999), os dados obtidos nas concessões de lavra ${ }^{1}$ demonstram que as minas no Brasil estão distribuídas regionalmente com $4 \%$ no norte, $8 \%$ no centro-oeste, $13 \%$ no nordeste, $21 \%$ no sul e $54 \%$ no sudeste.

A indústria mineral brasileira registrou um expressivo crescimento econômico financeiro ao longo da última década.

De acordo com o Instituto Brasileiro de Mineração - IBRAM (2014), a partir de 2000 o aumento da demanda por minerais impulsionou o valor da Produção Mineral Brasileira (PMB) que em 2014 é estimado em US\$ 43 bilhões. O IBRAM ainda registrou, com base em dados coletados junto às mineradoras, aplicação expressiva de US\$ 53,6 bilhões para o período de 2014 à $2018^{2}$, o que representa um avanço considerável para a indústria da mineração, tendo em vista que os investimentos aplicados estimulam outros setores produtivos, além de gerarem empregos, renda e tributos.

É inegável a relevância da mineração para o desenvolvimento socioeconômico do país, o qual disponibiliza para a sociedade recursos minerais essenciais para melhoria da qualidade de vida. Valentim Filho (2012, p. 374) explica que "o crescimento socioeconômico implica em maior consumo de bens minerais, tornando importante garantir a disponibilidade dos recursos demandados pela sociedade". Nesse contexto, existe uma relação direta entre desenvolvimento econômico, qualidade de vida e consumo de bens minerais.

\footnotetext{
${ }^{1}$ Lavra é o conjunto de operações coordenadas objetivando o aproveitamento industrial da jazida, desde a extração das substâncias minerais até o beneficiamento das mesmas. Disponível em:<http:/ /www.sebrae-sc.com.br/ideais/default.asp?vcdtexto $=2820$.

2 Dados extraídos do levantamento realizado pelo Instituto Brasileiro de Mineração em estudo intitulado: Informações e análises da economia mineral brasileira. Dados atualizados em fev. 2014. Disponível em: http://www.ibram.org.br.
} 
Não obstante, a atividade mineradora, “juntamente com o desenvolvimento socioeconômico que proporciona ao País, é potencialmente degradadora do meio ambiente"(COSTA, REZENDE, 2012, p. 771).

A mineração é por si só, uma atividade impactante, uma vez que promove a alteração das propriedades físicas, químicas e biológicas do meio onde está inserida. Souza e Fiorillo (2012, p.18), pactuam da mesma opinião e reconhecem que "não há como esconder que a exploração mineral, de alguma forma, pode causar danos ambientais, pois não existe risco zero nessa atividade econômica, aliás, em quase nenhuma atividade econômica".

Conforme opina Freire (2010, p. 60), "por sermos uma sociedade altamente dependente dos recursos minerais, necessário se faz regulamentar juridicamente o seu exercício".

Visando regulamentar a atividade minerária, existem regras que disciplinam essa atividade. Dessa forma, a Carta Magna considera os recursos minerais, inclusive aqueles localizados no subsolo, como bens da União (art. 20, IX), " a partir de um regime jurídico de domínio, que dissocia a propriedade do solo em relação à do subsolo, conforme art. 176, caput" (AYALA, 2012, p. 332). Através desse regime jurídico, há a oportunidade de particulares, sob o título de concessão ou autorização do Poder Público explorarem as jazidas e demais recursos minerais ${ }^{3}$.

O constituinte também introduziu outros artigos importantes relativos à mineração, como o art. 170, inciso VI, art. 186, inciso II, e o art. 225, que considera, em seu caput, o meio ambiente como um bem de uso comum do povo e essencial à sadia qualidade de vida.

O parágrafo segundo do art. 225, considera que, em caso de degradação é obrigatório o dever de recuperar, ao dispor que "a pessoa física ou jurídica que venha explorar recursos minerais será obrigada a recuperar o meio ambiente degradado". Ressalta-se que essa obrigação é imprescindível para manter o equilíbrio ecológico ou restabelecê-lo. Para tanto, é dever jurídico do órgão público, exigir a recuperação e indicar ou aprovar a solução técnica a ser observada na recomposição. Na opinião de Ribeiro (2006, p. 333):

Não existe incompatibilidade absoluta entre a prática da mineração e a preservação do meio ambiente, a despeito das atividades minerarias serem geralmente degradadoras do Meio Ambiente e, ás vezes, localmente poluidoras. Contudo, poderão coexistir, tratando-se, por óbvio, da mineração

${ }^{3}$ Constituição da República, art. $176, \S 1^{\circ}$. 
racional e responsavelmente conduzida, que respeita as normas técnicas regulamentares.

É notório que a atividade de mineração gera impactos, tanto de ordem ambiental, quanto social e econômico, exatamente por se tratar de bem natural não renovável. De acordo com Reis et al. (2005, p. 126), entende-se por impacto ambiental:

Qualquer consequência, adversa ou benéfica, que resulte ou que possa resultar da interação dos aspectos ambientais ou elementos de processos, operações, serviços e produtos de uma organização com o meio, sobre os quais ela tenha capacidade de exercer controle direto ou tenha capacidade de influenciar.

Sendo assim, a mineração deve ser realizada tendo como princípio o uso racional dos recursos naturais, seguindo os objetivos e princípios estabelecidos na Política Nacional do Meio Ambiente (PNMA) ${ }^{4}$, visando à manutenção do equilíbrio ecológico, a racionalização do uso do solo, do subsolo, da água e do ar, e a recuperação de áreas degradadas, entre outros.

\subsection{A extração de minério de areia no Brasil}

O solo brasileiro é composto de importantes depósitos de substâncias minerais, de metais ferrosos e não-ferrosos (metálicos), de gemas ${ }^{5}$, de água, de recursos energéticos e de minerais industriais, "estes predominantemente nãometálicos"(DARDENNE, SCHOBBENHAUS, 2003, p. 368).

$\mathrm{Na}$ indústria mineral, "os minerais são normalmente classificados em três classes: metálicos, não metálicos e energéticos” (LUZ; LINS, 2004).

Conforme preleciona Lins (2005, p. 14):

Os minerais metálicos, de imediato entendimento, são aqueles dos quais os metais são extraídos para suas aplicações. Os energéticos também não geram dubiedade por sua denominação, pois deles derivam as diversas modalidades de energia. [...] nos Minerais Industriais, considerados como minerais não

\footnotetext{
${ }_{4}^{4}$ Lei $\mathrm{n}^{\circ}$ 6.938, de 31 de agosto de 1981, dispõe sobre a Política Nacional do Meio Ambiente, seus fins e mecanismos de formulação e aplicação, e dá outras providências.

5 Pedras preciosas: diamante, esmeralda, safira, turmalina, opala, topázio, águas marinhas, ametista, etc. Segundo especialistas, "a terminologia "semi-preciosas" não deve ser mais usada" (LINS, 2005, p. 15).
} 
metálicos, diferentemente das classes dos metálicos e dos energéticos, os minerais se aplicam diretamente, tais como se encontram ou após algum tratamento, ou se prestam como matéria-prima para a fabricação de uma grande variedade de produtos.

Os produtos mais minerados no Brasil, em volume, são a areia e a pedra britada (classificados como minerais não metálicos). Conforme aponta Mancin (2012), "a produção anual é de 623 milhões de toneladas/ano, basicamente a cargo das pequenas empresas".

A areia é "uma substância mineral de desagregação de diversos tipos de rochas encontradas em vários tipos de depósitos, como aluviões e coluviões (GONÇALVES, 2008). Leinz e Amaral (1980), a definem como "um sedimento clástico inconsolidado, formado mais comumente por grãos com 0,2 a 2,0 mm de diâmetro e tendo como cores mais usuais o cinza, o amarelo ou o vermelho".

Segundo Matos e Lobo (1995, p. 2), "a classificação de areias pode ser feita em relação ao diâmetro de seus grãos, forma dos grãos e sua pureza". Quanto ao tipo, o Departamento Nacional de Produção Mineral - DNPM (2014) esclarece que a areia "pode ser aluvionar, comum, de barranco, de fundição, fina, fluvial, in natura, industrial, lavada, monazítica, para filtros, para jateamento, para perfuração, para vidro, quartzosa e silicosa".

A produção de areia ocorre em várzeas e leitos de rios, depósitos lacustres, mantos de decomposição de rochas, arenitos e pegmatitos decompostos. No Brasil, " $70 \%$ da areia é produzida em leito de rios e $30 \%$ nas várzeas" (VALVERDE, 2006, p. 37). A sua extração comumente se faz junto a matas ciliares, consideradas Áreas de Preservação Permanente.

Lelles et al. (2005, p. 440) divide a atividade de extração de areia em três fases: $1^{\mathrm{a}}$ fase de implantação, da qual fazem parte os processos de registro da extração de areia, aquisição de fatores de produção, contratação de mão de obra, abertura da rede viária, remoção da vegetação e instalação de estruturas para a extração de areia; $2^{a}$ fase de operação, a qual abarca os processos de retirada do material mineral, estocagem, drenagem, peneiramento, carregamento e transporte; e $3^{\mathrm{a}}$ fase de desativação, a qual compreende os processos de retirada das estruturas de extração de areia e recuperação e reabilitação da área.

Quando a areia é industrializada para o comércio, o produto passa pelas etapas de beneficiamento, embalagem e distribuição. O beneficiamento é considerado a etapa mais importante. 
De acordo com Ryzewski (2014) "o beneficiamento é todo o trabalho de tratamento e preparo da matéria-prima para a produção do produto final. Portanto, esse tipo de serviço visa a transformar e preparar um material para uma etapa seguinte de industrialização, o qual finalizará o produto pronto para ser comercializado".

Conforme sua constituição química, a areia tem várias aplicações. Nesse sentido, Gonçalves (2008) assinala as seguintes aplicações:

De rio: depósitos sedimentares que se formam nos leitos de alguns rios. Sua extração é realizada pôr dragas de sucção posicionadas em balsas, que bombeiam a água, contendo cerca de $5 \%$ a $10 \%$ de areia, para lagoas de decantação, de onde o material de retirado pôr pás carregadeiras, ou pelo sistema braçal. Em alguns casos a areia é classificada em fina, média e grossa; De cava: são depósitos aluviares em fundo de vales cobertos pôr capa de solo. Nesse caso, a areia é extraída pôr escavação mecânica ou pôr desmonte hidráulico, ou seja, a água é comprimida e atirada no barranco de areia; De britagem: é a areia de brita, proveniente do processo de classificação de britas; De escória: a escória de alto forno é resfriada bruscamente pôr jato de água, resultando em grãos em geral de granulometria inferior a $12,7 \mathrm{~mm}$. Este tipo de areia tem a composição bem diferente das areias proveniente das rochas. Tem como composição básica $\mathrm{SiO} 2, \mathrm{Al} 2 \mathrm{O} 3, \mathrm{CaO}$ e MgO; De praias e dunas: as areias das praias brasileiras não se usam, via de regra, em construção civil, pôr causa de grande finura e quantidade de cloreto de sódio. O mesmo é observado para areias de dunas próximas ao litoral.

Do mesmo modo, o Grupo Hobi Extração de Minérios (2012) descreve métodos comumente utilizados na extração de areia, sendo eles: a lavra de areia em encosta de morro, a lavra de areia em planícies aluviais e a lavra de areia em leitos de rio.

O método e a aplicação mais frequentes ocorrem nos rios, onde "a atividade prevê um ciclo sazonal de deslocamento contínuo ao longo dos leitos, seguindo o ciclo de exploração de deposições e sua renovação por processos naturais" (SOUZA, 2004, p. 3).

A areia de rios é um bem mineral que pode ser usado de forma "in natura", sem que haja a necessidade de qualquer tipo de tratamento, não sendo necessária adição ou eliminação de componentes ou substancias químicas. Submetida naturalmente a um processo de lixiviação ${ }^{6}$ pelas águas meteóricas,

${ }^{6}$ Processo de extração de uma substância presente em componentes sólidos através da sua dissolução num líquido. Disponível em: http://www.ibram.org.br. 
normalmente não apresenta quantidades significativas de sais, que são componentes indesejáveis na composição de argamassas (compostos hidrófilos). Dessa forma, representa uma matéria prima utilizada em larga escala na construção civil.

Os preços médios praticados "variam entre $\mathrm{R} \$ 15,50$ e $\mathrm{R} \$ 20,00 \mathrm{~m}^{3}$, sendo os maiores preços cotados para os materiais de maior granulometria, oriundos dos areais localizados mais a montante do rio", conforme dados apurados pelo Departamento Nacional de Produção Mineral - DNPM (2014).

Por fatores mercadológicos, em que o transporte corresponde a cerca de $1 / 3$ a $2 / 3$ do preço final do produto, a produção de areia impõe sua atuação próxima dos centros consumidores, caracterizando-se como uma atividade típica das regiões metropolitanas e urbanas.

À extração de areia, pressupõe-se a necessidade de licenciamento ambiental, que fica vinculada a determinadas leis e definições.

Não obstante, o índice de clandestinidade dessa atividade é significativo e preocupante. Com isso, os impactos ambientais provocados são grandes e descontrolados, degradando ambientes de delicado equilíbrio ecológico (dunas e manguezais), alterando canais naturais de rios e os aspectos paisagísticos. Geralmente, as cavas da extração de areia são utilizadas como bota-fora da construção civil e até mesmo como lixões.

Nesse contexto, embora a extração mineral de areia cumpra um importante papel no desenvolvimento social e econômico, ao gerar empregos e movimentar o mercado da construção civil, a atividade deve ser feita de maneira a minimizar os impactos ambientais.

A produção de bens minerais de areia é essencial no panorama socioeconômico do país, portanto, faz-se necessária a busca de aperfeiçoamentos para extração desses materiais de forma a se conseguir uma integração, sem ferir a paisagem e o meio ambiente.

\section{AS ÁREAS DE PRESERVAÇÃO PERMANENTE}

De acordo com o art. $3^{\circ}$, II, da Lei 12.651/20127 a Área de Preservação Permanente (APP) é a "área protegida, coberta ou não por vegetação nativa, com a função ambiental de preservar os recursos hídricos, a paisagem, a estabilidade geológica e a biodiversidade, facilitar o fluxo gênico de fauna e

7 BRASIL. Lei n. 12.651/2012. Dispõe sobre a proteção da vegetação nativa. 
flora, proteger o solo e assegurar o bem-estar das populações humanas", definição semelhante a que constava no art. $1^{\circ}, \S 2^{\circ}$, II da Lei 4.771 , antigo Código Florestal.

Pela definição legal, a área de preservação permanente poderá ou não ser coberta por vegetação nativa, devendo esta ser mantida por questões ambientais e também para preservar a segurança da sociedade.

São Áreas de Preservação Permanente, segundo o art. $4^{\circ}$ da Lei n. 12.651, com as modificações da Lei n. $12.727^{8}$, ambas de 2012, aquelas situadas em zonas rurais ou urbanas, com as seguintes categorias:

I - as faixas marginais de qualquer curso d'água (...); II - as áreas no entorno dos lagos e lagoas naturais (...); III - as áreas no entorno dos reservatórios d'água (...); IV - as áreas no entorno das nascentes e dos olhos d'água perenes, qualquer que seja sua situação topográfica (...); V - as encostas ou partes destas com declividade superior a $45^{\circ}$, equivalente a $100 \%$ (cem por cento) na linha de maior declive; VI - as restingas, como fixadoras de dunas ou estabilizadoras de mangues; VII - os manguezais, em toda a sua extensão; VIII - as bordas dos tabuleiros ou chapadas, até a linha de ruptura do relevo, em faixa nunca inferior a 100 (cem) metros em projeções horizontais; IX - no topo de morros, montes, montanhas e serras, com altura mínima de 100 (cem) metros e inclinação média maior que $25^{\circ}$, as áreas delimitadas a partir da curva de nível correspondente a $2 / 3$ (dois terços) da altura mínima da elevação sempre em relação à base (...); X - as áreas em altitude superior a 1.800 (mil e oitocentos) metros, qualquer que seja a vegetação; XI - em veredas, a faixa marginal, em projeção horizontal, com largura mínima de 50 (cinquenta) metros, a partir do espaço permanentemente brejoso e encharcado. (BRASIL, 2012).

Conforme ensina Machado (2013, p. 16), as Áreas de Preservação Permanente constantes do art. $4^{\circ}$ da Lei n. 12.651/12 (nova lei florestal), possuem pelo menos, seis características, quais sejam:

[...] a) é uma área e não mais uma floresta (no Código Florestal de 1965, com a redação original, tratava-se de "floresta de preservação permanente"). A área pode ou não estar coberta por vegetação nativa, podendo ser coberta por vegetação exótica; b) não é uma área qualquer, mas uma "área protegida", proibindo-se "qualquer utilização que comprometa a integridade dos atributos que justifiquem sua proteção" (Art. 225, § 1 , III, da Constituição); c) a área

${ }^{8}$ BRASIL. Lei n. $12.727 / 2012$. Altera a Lei n. 12.651/2012, que dispõe sobre a proteção da vegetação nativa. 
é protegida de forma "permanente", isto é, não é uma proteção descontínua, temporária ou com interrupções; d) é uma área protegida, com funções ambientais específicas e diferenciadas, apontadas na Lei n. 12.651/2012: funções ambientais de preservação abrangendo os recursos hídricos, a paisagem, a estabilidade geológica e a biodiversidade; função de facilitar o fluxo gênico de fauna e de flora; proteção do solo, evitando a sua erosão e conservando a sua fertilidade; finalidade de assegurar o bem-estar das populações humanas; e) a vegetação situada em Área de Preservação Permanente deverá ser mantida pelo proprietário da área, possuidor ou ocupante a qualquer título, pessoa física ou jurídica, de direito público ou privado; e f) a supressão indevida da vegetação na APP obriga o proprietário da área, o possuidor ou o ocupante, a qualquer título, a recompor a vegetação, e essa obrigação tem natureza real. Essa obrigação transmite se ao sucessor, em caso de transferência da propriedade ou da posse do imóvel rural.

Como se vê, as Áreas de Preservação Permanente possuem características que visam resguardar a integridade dos ecossistemas e a sadia qualidade do meio ambiente.

As Áreas de Preservação Permanente também são tuteladas pelo texto constitucional no art. 225, $\S 1^{\circ}$, III que incumbiu ao Poder Público, para assegurar o direito ao meio ambiente ecologicamente equilibrado, definir, em todas as unidades da Federação, espaços territoriais e seus componentes a serem especialmente protegidos, sendo a alteração e a supressão permitidas somente através de lei, vedada qualquer utilização que comprometa a integridade dos atributos que justifiquem sua proteção (BRASIL, 1988).

Nesse sentido, a regra é pela imodificabilidade da Área de Preservação Permanente, permitindo-se a intervenção ou supressão de vegetação, na forma da lei, valendo o exame de tópico específico atinente à impossibilidade de intervenção ou supressão de vegetação em áreas de preservação permanente.

\subsection{A intervenção ou supressão de vegetação em Áreas de Preservação Permanente}

Em regra, não será possível a supressão de vegetação em Áreas de Preservação Permanente. "Não por outro motivo a este espaço protegido foi dado o nome de área de preservação permanente e não de preservação provisória" (FIGUEIREDO, 2010, p. 230).

De acordo com Pinho (1999), a impossibilidade da supressão de vegetação em Área de Preservação Permanente ocorre em virtude dos inúmeros benefícios que ela proporciona, entre eles: 
A contenção de enchentes, principalmente em áreas de solos propícios ao processo de erosão; aumento da umidade relativa do ar; amenização da temperatura em climas tropicais e equatoriais; dispersão de poluentes e absorção de ruídos urbanos; funciona como elemento paisagístico na orientação urbana e rural; pode bloquear o vento indesejável em áreas urbanas; barreiras verdes também podem direcionar o vento para locais desejados e, ainda, ajuda na preservação de espécies de pássaros.

Conceição, Guerra e Pinheiro (2011, p. 85) possuem o mesmo entendimento, e consideram que as Áreas de Preservação Permanente "são essenciais em áreas rurais e urbanas".

Não obstante, a regra da intangibilidade das Áreas de Preservação Permanente não é absoluta. Sobre a possibilidade de supressão de vegetação em Áreas de Preservação Permanente, Granziera (2012, p. 67) afirma que “[...] o cumprimento da função ambiental das APP é a regra; só excepcionalmente poderá ser descaracterizada".

A Lei n. 12.651/12 traz situações especiais em seu art. $3^{\circ}$, VIII, IX, X, $8^{\circ}$ e $9^{\circ}$ em que se admite a exceção a impossibilidade de supressão de vegetação em Áreas de Preservação Permanente, de forma que o Poder Público poderá autorizá-la em caso de utilidade pública, de interesse social ${ }^{9}$ ou de baixo impacto ambiental, "permitindo, ainda, o acesso de pessoas e animais às áreas de preservação permanente para obtenção de água e para realização de atividades de baixo impacto ambiental" (ASSUNÇÃO, 2013, p. 77).

Revela-se de suma importância, neste contexto, a compreensão da expressão “interesse social”, pois o Poder Público poderá autorizar a supressão de áreas de preservação permanente para as atividades de pesquisa e extração de areia, argila, saibro e cascalho em caso de interesse social "devidamente comprovado, através de decisão motivada, em procedimento administrativo próprio, quando inexistir alternativa técnica e locacional" (CONCEIÇÃO, GUERRA, PINHEIRO, 2011, p. 86).

Nota-se, que a previsão da supressão total ou parcial da vegetação em Áreas de Preservação Permanente já havia sido tratada anteriormente em outros dispositivos como o art. $3^{\circ}, \S 1^{\circ}$ e o art. $4^{\circ}$ e seus parágrafos (redação dada

\footnotetext{
${ }_{9}$ Art. $3^{\circ}$ Para os efeitos desta Lei entende-se por:

(...)

IX - interesse social:

(...)

f) as atividades de pesquisa e extração de areia, argila, saibro e cascalho, outorgadas pela autoridade competente.
} 
pela MP n. 2.166-67/2001) da Lei n. 4.771/65 bem como a Resolução n 369 do CONAMA, porém, após a edição e publicação da Lei n. 12.651/12, referidos dispositivos ficaram em parte desprovidos de fundamento legal.

\subsection{As Áreas de Preservação Permanente como concretização da função socioambiental da propriedade}

A função socioambiental da propriedade foi reconhecida pela Constituição da República Federativa do Brasil de 1988, em seus artigos $5^{\circ}$, XXIII, 170, VI, $182, \S 2^{\circ}, 186$, II.

O direito de propriedade é exercido com as limitações que a legislação estabelece, ficando os proprietários ou posseiros obrigados a respeitarem as normas e regulamentos administrativos.

Quando se fala em função socioambiental da propriedade, na verdade se diz que ao proprietário de um bem se impõe o dever de exercer o seu direito de propriedade não apenas em seu próprio interesse, mas em benefício da coletividade, "sendo precisamente o cumprimento da função socioambiental que legitima o exercício do direito de propriedade pelo seu titular, conforme preceitua a regra constitucional" (DELLAZARI, 2012).

Para Ayala (2012, p. 300):

O principio da função socioambiental da propriedade, "superpõe-se à autonomia privada que rege as relações econômicas, para proteger os interesses de toda a coletividade em torno de um direito ao meio ambiente ecologicamente equilibrado. Somente a propriedade que cumpra a sua função social, possui proteção constitucional. Por essa razão, seu descumprimento importa a imposição de uma sanção: a desapropriação. Esta é suportada pelo proprietário exatamente em razão do exercício irresponsável do direito e da gestão inadequada dos recursos naturais.

As Áreas de Preservação Permanente, localizadas em cada posse ou propriedade, são bens de interesse nacional e espaços territoriais especialmente protegidos, com a função ambiental de preservar os recursos hídricos, a paisagem, a estabilidade geológica, a biodiversidade, o fluxo gênico de fauna e flora, proteger o solo e assegurar o bem-estar das populações humanas.

De acordo com Assunção (2013, p. 78), “as áreas de preservação permanente representam indubitavelmente a concretização da função socioambiental da propriedade rural". 
Nesses termos, ao estabelecer no art. 186, inciso II, que a propriedade rural cumpre a sua função social quando ela atende, entre outros requisitos, a utilização adequada dos recursos naturais disponíveis e à preservação do meio ambiente, o Constituinte impôs ao proprietário rural o dever de exercer o seu direito de propriedade em conformidade com a preservação da qualidade ambiental. E isto no sentido de que, se ele não o fizer, o exercício do seu direito de propriedade será ilegítimo, circunstância "que poderá conduzir a uma desapropriação" conforme preconiza Ayala (2012, p. 300).

Há uma obrigação legal de manterem-se as Áreas de Preservação Permanente com vegetação e os proprietários devem se sujeitar a ela, em qualquer circunstância, por força do princípio da função social e ambiental da propriedade, que lhes impõe o exercício do direito de propriedade em conformidade com as diretrizes de proteção do meio ambiente vigentes.

Com isso, a importância das Áreas de Preservação Permanente é indiscutível para a concretização do direito de propriedade, "o qual, somente é assim reconhecido quando atende suas funções socioambientais e o direito fundamental ao meio ambiente ecologicamente equilibrado" (ASSUNÇÃO, 2013, p. 79).

\section{A MINERAÇÃO DE AREIA EM ÁREAS DE PRESERVAÇÃO PERMANENTE}

A areia possui vasta utilidade na vida moderna, incluindo, em seus principais usos, os agregados ${ }^{10}$ para a construção civil. Assim como a pedra britada, a areia caracteriza-se por grandes volumes produzidos relativamente ao consumo de outros materiais.

Segundo Drew et al. (2002, p. 1), "excetuando-se os combustíveis fósseis, os agregados minerais possuem a mercadoria mais valiosa no mundo e a vida moderna sem estes recursos é inimaginável" (Tradução Nossa).

Nesse aspecto, sustentar uma economia em desenvolvimento requer um volumoso uso de agregados minerais.

Grande parcela de atividades humanas (comerciais, de lazer etc.) são transacionadas em instalações construídas a partir de agregados minerais, todavia,

\footnotetext{
${ }^{10} \mathrm{O}$ termo "agregados para construção civil" é empregado no Brasil para identificar um segmento do setor mineral que produz matéria-prima mineral bruta ou beneficiada de uso imediato na indústria da construção civil.
} 
a utilidade criada para a humanidade através da utilização de agregados minerais raramente é comparada favoravelmente com os impactos ambientais causados pela mineração.

A mineração de areia "ocorre em locais onde houve a deposição de material sedimentar erodido ao longo das eras geológicas" (ANNIBELLI, 2006, p. 4209). Geralmente, esses locais estão próximos a fundo de vales e aos rios, coincidindo muitas vezes com as matas ciliares, consideradas Áreas de Preservação Permanente.

Souza et al. (2004, p. 3), enxerga as Áreas de Preservação Permanente, como um instrumento de garantia da "estabilização das margens de cursos d'água, atuando no controle da erosão do solo e na manutenção da vazão e qualidade da água, atenuando o carreamento de sedimentos, nutrientes e produtos químicos do solo para o ambiente aquático", que podem afetar a qualidade da água e/ou diminuir a vida útil dos reservatórios.

Nesse passo, as Áreas de Preservação Permanente devem ser preservadas, no entanto, existem diversas atividades econômicas responsáveis pela degradação e destruição dessas áreas, principalmente a agricultura e a pecuária, a extração de madeira, as atividades industriais, a expansão urbana desregrada, a construção de estradas e pontes e as atividades de mineração. Essa última, conforme explicam Ribeiro e Mendes (2013, p. 29), "contribui sobremaneira para a degradação das áreas pela movimentação de grandes volumes de terra, suprimindo a vegetação, afugentando a fauna, modificando a topografia e destruindo a paisagem".

Matos e Lobo (1995, p. 3) observam que confirmadas em campo, à extração de areia em Áreas de Preservação Permanente pode causar várias formas de degradação ambiental, entre elas:

Desmatamento de APP para implantação de caixas, pátios e acessos; corte de taludes e aterros para a implantação de caixas; erosões e assoreamento em acessos; emissão de ruídos na operação de dragas; erosão de taludes em pontos de retorno d'água com sedimentos da caixa para o leito; turbidez da água de drenagem, principalmente em caixas de areia de pequeno porte, ocasionando problemas de aproveitamento; contaminação da água de drenagem por óleo combustível, graxas e outros efluentes de forma difusa e/ ou acidental; compactação do solo pelo tráfego de máquinas pesadas nos acessos; contaminação de solos e água por destinação inadequada de resíduos sólidos. 
As atividades de mineração de areia normalmente necessitam de um alto volume de água, o que leva a ocupar áreas próximas aos rios. Em algumas situações, ocorre a retirada de materiais diretamente de áreas originariamente ocupadas por matas ciliares, consideradas de preservação permanente. Dessa forma, degradam-se as matas ciliares e desfiguram-se as barrancas dos rios.

Além disso, conforme explica Annibelli (2006, p. 4210), utilizam-se "grandes quantidades de água para lavagem de minérios de areia, essa lavagem gera resíduos que geralmente fluem para os rios, causando assoreamento e poluição. A retirada de água e os canais de transporte de resíduos da lavagem contribuem para destruir a mata ciliar".

A Lei n. 12.651/12 prevê em seus artigos $3^{\circ}$, VIII, IX, X, $8^{\circ}$ e 9, a supressão de vegetação em Áreas de Preservação Permanente e sua utilização com finalidade econômica, em casos excepcionais, de utilidade pública, interesse social ou baixo impacto ambiental.

Nesse contexto, consolida-se o entendimento que as atividades de pesquisa e extração de areia, argila, saibro e cascalho, outorgadas pela autoridade competente, são consideradas de interesse social, a partir dos art. $3^{\circ}$, IX, alínea f, e $8^{\circ}$ da Lei n. 12.651/2012, para fins de supressão de vegetação em Áreas de Preservação Permanente.

A respeito do tema, Carneiro (2009, p. 336) faz a seguinte consideração:

A atividade de mineração, além de ser desenvolvida no interesse nacional, gênero do qual a utilidade pública é espécie, haja vista o disposto no artigo $176, \S 1^{\circ}$ da Constituição Federal, possui como outra importante característica a rigidez locacional, o que impõe ao minerador o ônus de explorar a jazida mineral no local de sua ocorrência geológica natural, local este que nem sempre coincide com a área onde a mineração seria mais conveniente do ponto de vista da conservação dos ecossistemas naturais.

Dessa forma, para a supressão de vegetação em Áreas de Preservação Permanente faz-se necessária a prévia comprovação da inexistência de alternativas técnicas e locacional aos projetos ou atividades, inexistência de riscos de agravamentos de enchentes, erosão ou movimentação de rochas, bem como a apresentação de medidas mitigadoras e compensatórias ao órgão competente.

Em virtude dos possíveis impactos ambientais que pode ocasionar, a atividade de mineração de areia sujeita-se ao licenciamento ambiental. A 
Resolução do CONAMA n ${ }^{\circ}$ 10/1990 estabelece que a exploração de areia deva suceder licenciamento ambiental pelo órgão executivo estadual ou federal de meio ambiente. Já a Resolução do CONAMA n 237/1997, regulamenta o licenciamento ambiental que foi previsto pela Lei 6.938/1981 (Política Nacional do Meio Ambiente).

Em caso de o minerador praticar a atividade sem a devida autorização ou licença, incorrerá na prática de crime contida na norma do art. 44 da Lei $n$. 9.605/1998, podendo cumprir a pena de detenção no período de seis meses a um ano, além do pagamento de multa. Lado outro, se o minerador estiver munido da devida autorização ou licença, a ação de extrair minerais em Áreas de Preservação Permanente não se configurará como crime, sendo uma atividade perfeitamente lícita.

Vale ressaltar que em cumprimento à função socioambiental da propriedade, caso o minerador venha causar desmatamento em Área de Preservação Permanente, ficará obrigado a recompor a área de vegetação, independentemente da sanção criminal.

Há uma obrigação legal de manterem-se as Áreas de Preservação Permanente com vegetação e os mineradores devem se sujeitar a ela, em qualquer circunstância, por força do princípio da função socioambiental da propriedade, e em conformidade com as diretrizes de proteção do meio ambiente vigentes.

Nesse sentido, é possível vislumbrar a ocorrência da atividade minerária em Áreas de Preservação Permanente, desde que atendidos os preceitos estabelecidos na Lei n. 12.651/12 (nova lei florestal) e na Lei Complementar n. 140/11, relativa ao licenciamento ambiental.

\section{A IMPORTÂNCIA DA MINERAÇÃO DE AREIA NO CONTEXTO SOCIOECONÔMICO DO PAÍS}

No Brasil, "por volta de 1.700 municípios (30,6\% do total) recebem recursos financeiros da Compensação Financeira pela Exploração Mineral CFEM" (ENRÍQUEZ, 2007). O Sumário Mineral/2010 publicado pelo DNPM (Departamento Nacional de Produção Mineral 2011) apresenta o comportamento de mercado de 50 (cinquenta) substâncias minerais selecionadas, as quais representam mais de $90 \%$ do valor da produção mineral do Brasil em 2009, incluindo-se aí o mineral de areia. 
A mineração de areia é uma atividade economicamente importante ao país principalmente porque oferece materiais para a indústria e construção civil. Além disso, Filho $(2009$, p. 62) enfatiza que "a extração de areia representa uma importância atividade na geração de emprego e renda, direta e indiretamente.

A areia obtida da extração pode ser usada para fundição, fabricação de vidros, silicatos, cerâmicas, construção de campos esportivos, filtragens, entre outras.

Segundo Castro (1992, p. 1), "não se admite a sobrevivência humana sem a utilização dos bens minerais, sobretudo, daqueles necessários à construção civil".

Annibell (2006, p. 4209) explica que:

O aproveitamento econômico de recursos naturais e minerais está inserido nas práticas de estratégia para o desenvolvimento territorial. Os processos de crescimento populacional, de modernização e de urbanização aumentam a demanda por recursos do setor de extração mineral voltado para a construção civil. Esta exploração indica o aumento do número de obras e caracteriza-se como atividade que proporciona o desenvolvimento socioeconômico para os agentes afetados direta ou indiretamente pelo empreendimento. Juntamente com todo o processo de utilização do recurso, desencadeiam questões de ordem social, ambiental e, também, econômica. As interferências de determinada atividade culminam em reflexos na sociedade e, portanto, devem ser previstos, dentro do possível, na elaboração de estudos ambientais e territoriais.

Os agregados de minério, "por sua importância para os setores de habitação (déficit habitacional), saneamento e transportes, são considerados como bens minerais de uso social" (PENNA, 2010).

A demanda por agregados da construção civil cresceu expressivamente em catorze anos, partindo de "460 milhões de toneladas em 1997 para 673 milhões de toneladas em 2011, crescimento correspondente a 46,2\%". Já no período de 2001 a 2011, o crescimento da demanda foi de $92,3 \%$ correspondente a uma taxa de crescimento anual de $6,8 \%$ a.a", o que representa um considerável aumento no consumo (IBRAM, 2012, p. 17).

No Brasil, há o destaque para a produção de areia comercializada bruta, a qual atingiu no ano de 2005 "um total de $141.084 .561 \mathrm{~m}^{3}$, cerca de $\mathrm{R} \$$ 1.923.468.414, com um investimento de somente R\$25.670.006” (DNPM, 2014). 
Seus maiores produtores nacionais em 2005 são representados pelos principais Estados do Sudeste do Brasil: São Paulo, com 49.964.236 m³ , Minas Gerais, com 13.755.434 m³ , seguido do Rio de Janeiro, com $11.228 .910 \mathrm{~m} 3 \mathrm{e}$ representam respectivamente, $35,4 \%, 10 \%$ e $8 \%$ da produção nacional (DNPM, 2014). Tal atividade gerou em 2005 no país 9.236 empregos, sendo eles empregados $(7.911 ; 85,6 \%)$, terceirizados $(1.269 ; 13,7 \%)$ e cooperativados $(56$; $0,6 \%)$.

O principal mercado consumidor de areia no Brasil é a construção civil, diretamente $(62 \%)$ e todos os seus subsetores, tais como construção/manutenção de estradas $(3.66 \%)$, artefatos de cimento $(1.25 \%)$ e aterro $(0.96 \%)$.

Com isso, o setor de mineração de areia vive um momento virtuoso no Brasil, sustentado principalmente, pelos investimentos em obras de infraestrutura e habitação. O bônus demográfico é outro componente positivo na sustentabilidade desse crescimento.

Nesse contexto, diante das informações levantadas em estudo, resta evidente a essencialidade da mineração de areia no contex to social e econômico do Brasil.

\section{IMPACTOS SOCIOECONÔMICOS E AMBIENTAIS CAUSADOS PELA MINERAÇÃO DE AREIA}

A atividade de mineração de areia promove impactos negativos e positivos que ocorrem a nível social, econômico e ambiental.

Como impactos positivos, vislumbra-se a geração de empregos diretos, bem como de empregos indiretos que a atividade proporciona, como exemplo: empregados da construção civil, caminhoneiros que transportam a areia, pessoas ligadas ao comércio de materiais de construção, além de profissionais liberais como geólogos, advogados e contadores.

Concomitantemente, a atividade minerária gera impostos, "que revertem em serviços à população, possibilitando que se dê continuidade a obras e projetos que visem melhorar as condições de vida, proporcionando bem estar à população em geral" (ANNIBELLI, 2006, p. 4213). Ainda, há uma dinamização do setor comercial, devido à aquisição de fatores de produção, proporcionando o aquecimento da economia local.

Normalmente, esses impactos positivos também repercutem na região entorno à área mineirada, uma vez que a areia extraída é comercializada e utilizada, e de modo geral, é geradora de riquezas. 
Como se vê, as atividades de extração mineral de areia cumprem um importante papel no desenvolvimento social e econômico do país, gerando empregos e movimentando o mercado da construção civil, mas segundo Brandt (1988), "são responsáveis por impactos ambientais muitas vezes irreversíveis".

Silva (2007, p. 3) explica que "assim como toda exploração de recurso natural, a atividade de mineração provoca impactos no meio ambiente seja no que diz respeito à exploração de áreas naturais ou mesmo na geração de resíduos".

A extração mineral de areia trata-se de uma atividade fortemente poluente. Para Terminski (2012, p. 31) "em vez de contribuir para o bem-estar das comunidades locais, "a extração de recursos leva a um crescente número de reassentamentos, a destruição ambiental, e uma deterioração da situação de grupos marginalizados"' (Tradução Nossa).

Entre os danos causados pela mineração de areia podem-se enumerar: o desmatamento de Áreas de Preservação Permanente para implantação de caixas, pátios e acessos; a alteração dos cursos dos rios e o seu assoreamento causados pela deposição de solo no fundo do rio pela ausência da mata ciliar para segurar o solo das margens; os ruídos na operação de dragas; compactação do solo causada pela retirada da mata e o trânsito de máquinas; a fuga da fauna como consequência do barulho e movimentação no local; a poluição das águas com o uso inadequado de combustíveis fósseis; e as queimadas.

Em pesquisa in locu, realizada entre os meses de maio e junho de 2006 no Rio Tibagi, em Ponta Grossa/PR, os geógrafos Mariana Annibelli e Daniel Telles, perceberam, que muitos moradores de áreas próximas ao rio, tinham hábitos de passeio, descanso, apreciação da paisagem, pesca e banhos, porém, com o surgimento de problemas ambientais decorrentes da mineração de areia, especialmente a poluição das águas, o desmatamento, a perda da vida e o acúmulo de lixo, os moradores estão afastando-se paulatinamente. Além disso, observou-se através de entrevistas, que o sentimento de ligação, elo, entre os moradores das áreas afetadas pela mineração está mudando, uma vez que “ $36,3 \%$ dos entrevistados disseram já não possuir nenhuma relação com o Rio; enquanto $18,1 \%$ disseram já ter possuído; $22,7 \%$ possuíam pouca ligação; enquanto $22,7 \%$ dos entrevistados ainda mantinham bastante relação com o mesmo" (ANIBELLI, 2006, p. 4215).

Em outra região, os biólogos Camila Lima, Marcos Santana e Nilton Valle analisaram o uso das dragas e sua relação com a degradação ambiental em três pontos de extração no município de Campestre de Goiás/GO: Ponto I, 
localizado na Fazenda Palmeiras, córrego das Pedras, Ponto II, localizado na fazenda Palmeiras, Leito do Rio Santa Maria e Ponto III, localizado na fazenda Palmeiras, Leito do Rio dos Bois. Após as pesquisas, observou-se que em todos os pontos, ocorreram alterações na qualidade das águas e flora, fauna terrestre, comprometimento de jazidas e alto fluxo de carregamento e transporte. Segundo os pesquisadores "as dragas tem uma função social relevante, principalmente econômica, no entanto, trazem graves problemas ambientais, mais especificamente do Rio Santa Maria estes impactos são notáveis", pelo fato das extrações ocorrerem em localidades próximas uma da outra (LIMA; SANTANA; VALLE, 2012, p. 31).

Valverde e Sintoni (1994, p. 31) argumentam que a "mineração de areia torna-se problemática, pois se constitui na busca de matéria prima de baixa relação preço/volume, sendo seu principal fator limitante a distância do mercado consumidor". Além disso, em virtude do baixo valor agregado da areia, os empreendedores são estimulados, do ponto de vista econômico, a postergar indefinidamente sua adequação ambiental, para conseguir manter sua lucratividade.

Nesse contexto, a extração de minério de areia ocorre em áreas o mais próximo possível dos centros de consumo (centros urbanos na sua maioria), o que potencializa situações de conflito entre a mineração de areia e o uso urbano do espaço, ocasionando outro impacto negativo visível que é a transformação do local minerado, e a consequente perda de identidade entre as pessoas e o lugar devido à poluição e perturbação na área.

A mineração de areia, embora necessária, altera a paisagem do lugar minerado e degrada o meio ambiente, e nesse passo, é imprescindível a busca de aperfeiçoamentos para extração desses materiais, cuja importância econômica e social é indiscutível, de forma a se conseguir uma integração, sem ferir a paisagem e o meio ambiente.

De acordo com Fernandes (2008, p. 20), o desenvolvimento e o ambiente “devem ser almejados de forma sustentável para que as pessoas possam viver de forma digna com melhoria da qualidade de vida, através do desenvolvimento econômico e da manutenção dos recursos ambientais".

Assim sendo, justificam-se as atenções para a realização de licenciamentos ambientais nas áreas onde ocorre à extração mineral de areia, visando avaliar suas limitações, vulnerabilidade e sustentabilidade, de forma que os impactos negativos sejam minimizados em busca do desenvolvimento sustentável. 


\section{CONSIDERAÇÕES FINAIS}

A partir da elaboração deste artigo, foi possível observar que a mineração é considerada um dos setores básicos da economia do Brasil.

O solo brasileiro é composto de importantes depósitos de substâncias minerais, de metais ferrosos e não-ferrosos (metálicos), de gemas, de água, de recursos energéticos e de minerais industriais, onde estão inseridos os minérios de areia.

Geralmente, a extração mineral de areia ocorre próxima a fundo de vales e rios, coincidindo muitas vezes com as matas ciliares, consideradas Áreas de Preservação Permanente (APP).

Em a regra as Áreas de Preservação Permanente não podem ser modificadas, todavia, permite-se a supressão de vegetação em Áreas de Preservação Permanente e sua utilização com finalidade econômica, em casos excepcionais, de utilidade pública, interesse social ou baixo impacto ambiental, conforme o art. $3^{\circ}$, VIII, IX, X, $8^{\circ}$ e $9^{\circ}$ da Lei n. 12.651/12.

Neste contexto, consolida-se o entendimento, que as atividades de pesquisa e extração de areia outorgada pela autoridade competente é considerada de interesse social, a partir dos art. $3^{\circ}$, IX, alínea $\mathrm{f}, \mathrm{e} 8^{\circ}$ da Lei n. $12.651 / 12$, para fins de supressão de vegetação em áreas de preservação permanente.

Vale ressaltar que em cumprimento à função socioambiental da propriedade, caso o minerador venha causar desmatamento em Área de Preservação Permanente, ficará obrigado a recompor a área de vegetação, independentemente da sanção criminal.

O desenvolvimento da atividade minerária incorpora um conjunto de efeitos ambientais próprios da mineração, abrangendo intervenções significativas sobre os recursos naturais e os interesses sociais e econômicos.

Nesse passo, as atividades de extração mineral são de grande importância para o desenvolvimento social, pois geram empregos e renda, mas também são responsáveis por impactos ambientais negativos, como a alteração dos cursos dos rios e o seu assoreamento; a erosão do solo; a fuga da fauna; a poluição das águas e dos solos; e as queimadas.

Estes se tornam mais visíveis com a dinamização do processo de industrialização e o crescimento das cidades, que aceleram os conflitos entre a necessidade de buscar matérias-primas e a conservação do meio ambiente. 
Para a concretização do Direito ao Desenvolvimento Sustentável, é necessária a inserção de princípios que irão resguardar os recursos ambientais e permitir que a economia se desenvolva de forma racional.

Os impactos ambientais podem ser minimizados ou até mitigados com uma tecnologia de extração mais adequada, todavia, não são apenas os impactos ambientais que devem ser mitigados, mas também o social e socioambiental.

Diante do exposto, conclui-se que é possível a ocorrência da atividade minerária em Áreas de Preservação Permanente, desde que a atividade seja desenvolvida de maneira sustentável, melhorando a qualidade ambiental do empreendimento e sejam atendidos os preceitos estabelecidos na Lei n. 12.651/ 12 (nova lei florestal) e na Lei Complementar n. 140/11, relativa ao licenciamento ambiental.

\section{REFERÊNCIAS}

ANNIBELLI, Mariana Baggio. Mineração de areia e seus impactos sócio-econômico-ambientais. In: Congresso Nacional do Conselho Nacional de Pesquisa e Pós-Graduação em Direito - CONPEDI. Manaus: p.4205-4217, 2006.

ANTUNES, Paulo de Bessa. Áreas protegidas e direitos constitucionais. In: SAMPAIO, Rômulo; LEAL, Guilherme; REIS, Antônio Augusto (org.). Tópicos de Direito Ambiental: 30 anos da Política Nacional do Meio Ambiente. Rio de Janeiro: Editora Lumen Juris, 2011.

ASSUNÇÃO, Haroldo Celso de. As áreas rurais consolidadas no código florestal de 2012: uma análise sob a perspectiva da função socioambiental da propriedade. Dissertação (Programa de PósGraduação em Direito Ambiental e Desenvolvimento Sustentável), Escola Superior Dom Helder Câmara. Belo Horizonte: 2013. Disponível em: $<$ http:// www.domhelder.edu.br/uploads/dissertaoharoldocelsodeassuno.pdf $>$. Acesso em: 20 mar. 2015.

AYALA, Patryck de Araújo. Deveres ecológicos e regulamentação da atividade econômica na Constituição brasileira. In: CANOTILHO, José 
Joaquim Gomes; LEITE, José Rubens Morato (Org.). Direito

Constitucional Ambiental Brasileiro. 5. ed. São Paulo: Saraiva, 2012.

BRANDT, Wilfred. Avaliação de cenários em planos de fechamento de minas. In: DIAS, L. E.; MELLO, J. W. V. (Eds.). Recuperação de áreas degradadas. Viçosa: p. 131-134, 1998.

BRASIL. Congresso Nacional. Lei n. 12.651 de 25 de maio de 2012. Dispõe sobre a proteção da vegetação nativa. Disponível em: < http:/ /www.planalto.gov.br/ccivil_03/_Ato2011-2014/2012/Lei/L12651.htm>. Acesso em: 20 jan. 2015.

BRASIL. Congresso Nacional. Lei n. 12.727 de 17 de outubro de 2012. Altera a Lei n. 12.651, de 25 de maio de 2012, que dispõe sobre a proteção da vegetação nativa. Disponível em: <http:// www.planalto.gov.br/ccivil_03/_Ato2011-2014/2012/Lei/L12727.htm>. Acesso em: 25 fev. 2015.

BRASIL. Constituição (1988). Constituição da República Federativa do Brasil. Brasília, DF: Senado, 1988.

BRASIL. Lei ${ }^{\circ}$ 9.605, de 12 de fevereiro de 1998. Disponível em:<http:// www.planalto.gov.br/ccivil_03/leis/19605.htm> Acesso em: 27 fev. 2015.

BRASIL. Resolução CONAMA Nº 001, de 23 de janeiro de 1986. Disponível em:<http://www.mma.gov.br/port/conama/res/res86/ res0186.html> Acesso em: 27 fev. 2015.

BRASIL. Resolução CONAMA 369/06 de 28 de março de 2006. Dispõe sobre os casos excepcionais, de utilidade pública, interesse social ou baixo impacto ambiental, que possibilitam a intervenção ou supressão de vegetação em Área de Preservação Permanente-APP. Disponível em: <www.cetesb.sp.gov.br/.../federal/.../2006_Res_CONAMA_369.pdf>. Acesso em: 28 fev. de 2015.

CARNEIRO, Ricardo. Direito Ambiental: uma abordagem econômica. Rio de Janeiro: Editora Forense, p. 336, 2001. 
CLEMENTE, Carlos Magno Santos; LEITE, Marcos Esdras Leite; PEREIRA, Deborah Marques. Estudo comparado da área de mineração no município de Itabira/MG nos anos de 1985, 1997 e 2007. Observatorium: Revista Eletrônica de Geografia. Uberlândia: v.5, n.13, p. 84-100, jun. 2013.

CONCEIÇÃO, Maria Collares Felipe; GUERRA, Isabella Franco; PINHEIRO, Gabriela Guimarães. Área de preservação permanente e reserva legal florestal no código florestal brasileiro. In: AMARAL, Flávio; COUTINHO, Ronaldo (coord.). Tutela jurídica das áreas protegidas (Lei n. 9.985/2000). Rio de Janeiro: Lumen Juris, 2011.

COSTA, Beatriz Souza; FIORILLO, Celso Antônio Pacheco. Tutela jurídica dos recursos ambientais minerais vinculada ao conceito democrático de segurança nacional. Revista Veredas do Direito. Belo Horizonte: v. 9, n.18, p. 9-35, jul./dez. 2012.

COSTA, Beatriz Souza; REZENDE, Elcio Nacur. Meio Ambiente do Trabalho e a Saúde do Trabalhador na Mineração Brasileira. Revista do Instituto do Direito Brasileiro. Lisboa: ano 1, n. 2, 2012. Disponível em: $<$ http://www.idb-fdul.com/uploaded/files/2012_02_0759_0792.pdf: $>$. Acesso em: 13 mar. 2015.

COSTA, Solange Maria Santos; AMORIM, Lauro Ângelo Dias de. Mineração e espações territoriais especialmente protegidos. In: Direito minerário: Estudos. GANDARA, Leonardo et al. (coord.). Belo Horizonte: Del Rey, 2011.

DARDENNE, Marcel Auguste; SCHOBBENHAUS, Carlos. Depósitos Minerais no Tempo Geológico e Épocas Metalogenéticas Mineral. IN: BRASIL. Ministério das Minas e Energia. Geologia, Tectônica e Recursos Minerais do Brasil: textos, mapas \& SIG. Luiz Augusto Bizzi et al. (org.). Brasília: Serviço Geológico do Brasil - CPRM, 2003.

DELLAZARI, Juliana Cristina. Áreas de preservação permanente e reserva legal. Disponível em: < www.buscalegis.ufsc.br/revistas $>$. Acesso em: 08 fev. 2015. 
DEPARTAMENTO NACIONAL DE PRODUÇÃOMINERAL - DNPM. Extração de areia. Brasília: 2014. Disponível em: <http:www.dnpm.gov.br $>$. Acesso em: 16 jan. 2015.

DEPARTAMENTO NACIONAL DE PRODUÇÃO MINERAL - DNPM. Sumário Mineral - Edições 2011. Brasília: 2011. Disponível em: $<$ http:www.dnpm.gov.br>. Acesso em: 16 jan. 2015.

DREW, Lawrence; LANGER, William; SACHS, Janet. Environmentalism and natural aggregate mining. Natural Resources Research: v.11, p. 1928, 2002. Disponível em: < http://link.springer.com/article/10.1023/ A\%3A1014283519471>. Acesso em: 20 mar. 2015.

ENRÍQUEZ, Maria Amélia Rodrigues da Silva; DRUMMOND, José Augusto. Social-environmental certification: sustainable development and competitiveness in the mineral industry of the Brazilian Amazon. Natural Resources Forum, v. 31. USA: Blackwell Publishing Ltd., p. 71 - 86, 2007.

FARIAS, Carlos Eugênio Gomes. Mineração e Meio Ambiente no Brasil. Relatório Preparatório para o CCGE/ Programa das Nações Unidas para o Desenvolvimento PNUD. Contrato 2002. Disponível em: $<$ http:// www.cgee.org.br/arquivos/estudo011_02.pdf>. Acesso em: 13 fev. 2015.

FERNANDES, Jeferson Nogueira. O Direito Fundamental ao Desenvolvimento Sustentável. Revista Direitos Fundamentais \& Democracia. Curitiba: n. 3, 2008. Disponível em: $<$ http://app.vlex.com/\#WW/ search/content_type:4/resolu\%C3\%A7\%C3\%A3o+conama+369/vid/ 69504335> Acesso em: 10 fev. 2015.

FERREIRA, Gilda Carneiro; DAITX Elias Carneiro. A mineração de areia industrial na Região Sul do Brasil. Revista Escola de Minas. Ouro Preto: v. 56, , Jan./Mar., 2003.

FIGUEIREDO, Guilherme José Purvin de. A propriedade no direito ambiental. São Paulo: Editora Revista dos Tribunais, 4 ed., 2010. 
FILHO, José Marcos Valentim. A mineração em ambientes considerados como patrimônio cultural: o caso das áreas tombadas. ORBIS: Revista Científica. Campina Grande: v. 3, n. 1. 2012.

FREIRE, William. Código de Mineração Anotado. Belo Horizonte: Mandamentos, 2010.

GONÇALVES, Sérgio Penha. Gênese e formação da areia. 2008. Disponível em $<$ http://www.grupoescolar.com/pesquisa/areia.html $>$. Acesso em: 20 mar. 2015.

GRANZIERA, Maria Luiza Machado. Planos de drenagem urbana e perspectivas para a proteção das Áreas de Preservação Permanente. Revista de Direito Econômico e Socioambiental. Curitiba: v. 3, n. 1, p. 43-78, jan.-jun. 2012.

GRUPO HOBI. Extração de minérios. 2012. Disponível em: <http:// grupohobi.com.br/mineracao/>. Acesso em: 25 fev. 2015.

INSTITUTO BRASILEIRO DE MINERAÇÃO - IBRAM. Disponível em $<$ http://www.ibram.org.br/sites/1300/1382/00002806.pdf > . Acesso em: 10 mar. 2015.

LEINZ, Viktor; AMARAL, Sergio Estanislau do. Geologia Geral. São Paulo, $8^{\text {a }}$ ed. 1980.

LELLES, Leandro Camillo de. Perfil ambiental qualitativo da extração de areia em cursos d' água. Revista Árvore. Viçosa: v. 29, n. 3, p.439-444, 2005 .

LIMA, Camila Araújo de; SANTANA, Marcos Aurélio; VALLE, Nilton Carlos do. Impactos causados por extração de areia em três pontos no município de Campestre de Goiás/GO. In: IV Seminário de Pesquisas e TCC da FUG. 2012. Disponível em: $<$ http://fug.edu.br/2010/pdf/tcc/ IMPACTOS $\% 20$ CAUSADOS\%20POR \%20EXTRACAO\%20DE\%20AREIA \%20EM\%20TRES\%20PONTOS.pdf>. Acesso em: 16 mar. 2015. 
LINS, Fernando Antônio Freitas. Panorama da produção e consumo de rochas e minerais industriais no Brasil. In: Comunicação Técnica (Centro de Tecnologia Mineral Ministério da Ciência e Tecnologia). Rio de Janeiro: nov. 2005.

LUZ, Adão Benvindo; LINS, Fernando Antônio Freitas. Introdução ao tratamento de minérios. In: Tratamento de Minérios. 4 ed. Comunicação Técnica (Centro de Tecnologia Mineral Ministério da Ciência e Tecnologia). Rio de Janeiro: cap.1, p.1-16, 2004.

MACHADO, Paulo Affonso Leme. Inovações na legislação ambiental brasileira: a proteção das florestas. Revista Veredas do Direito. Belo Horizonte: v.10, p.11-21, Jan./Jun. 2013.

MACHADO, Paulo Affonso Leme. Legislação Florestal (Lei 12.651/ 012) e Competência e Licenciamento Ambiental (Lei Complementar 140/2011). São Paulo: Malheiros, 2012.

MANCIN, Rinaldo César. Estagnação das pesquisas na área gera expectativas negativas. 2012. Disponível em: $<$ http://www.sebraesc.com.br/ideais/default.asp?vcdtexto=2820ý>. Acesso em: 14 mar. 2015.

MARQUES, Eduardo Duarte. Impactos da mineração de areia na bacia sedimentar de Sepetiba, RJ: estudo de suas implicações sobre as águas do aqüífero Piranema. Tese (Doutorado em Geociências) Universidade Federal Fluminense. Niterói: 2010. Disponível em: $<$ http:// www.cprm.gov.br/publique/media/dou_marques.pdf $>$ Acesso em: $15 \mathrm{fev}$. 2015.

MATOS, Silvio Costa; LOBO, Luiz de Morais. Areia para Construção Civil em Goiás: perfil da produção, danos ambientais e propostas de mitigação. In: Anais do $5^{\circ}$ Simpósio e Geologia do Centro-Oeste. Goiânia: p.2-3, 1995.

MELO, João Carlos de. Mineração e meio ambiente: é possível harmonizar? In: I Congresso Brasileiro de Mineração da Amazônia. Belém: 2008. Disponível em:<_www.ibram.org.br/sites/1300/1382/00000065.docý>. Acesso em: 18 jan. 2015. 
NOBRE FILHO, Pedro Aguiar. Impactos Ambientais Causados Pela Extração de Areia no Canal Ativo do Rio Canindé -Paramoti Ceará. Dissertação (Programa de Pós-Graduação em Geologia). Universidade Federal do Ceará. Fortaleza: 2009.

NUPEC. Material de construção. In: Informativo econômico (Faculdade de ciências econômicas, administrativas e contábeis de Divinópolis). Divinópolis: ano VIII, 2014.

OLIVEIRA, Flávia Lopes; Edson Farias MELLO. A mineração de areia e os impactos ambientais na bacia do rio São João, RJ. Revista Brasileira de Geociências. Rio de Janeiro: p. 374-389, 2007. Disponível em:<http://www.sbgeo.org.br> Acesso em: 13 mar. 2015.

PINHO, Paulo Maurício. Aspectos Ambientais da Implantação de "Vias Marginais" em Áreas Urbanas de Fundo de Vale. Dissertação (Programa de Pós Graduação em Engenharia Urbana), Universidade Federal de São Carlos. São Carlos: 1999.

REIS, Fábio Augusto Gomes Vieira. Diagnóstico ambiental em minerações de areia e argila no rio Jaguari Mirim, município de São João da Boa Vista (SP). Revista de Engenharia ambiental. Espírito Santo do Pinhal: v. 2, n. 1, p. 115-134, jan./dez. 2005.

RIBEIRO, Carlos. Direito minerário escrito e aplicado. Belo Horizonte: Del Rey, 2006.

RIBEIRO, José Cláudio Junqueira; MENDES, Samuel Felisbino. A participação no fechamento de mina no direito comparado. Revista Veredas do Direito. Belo Horizonte: v.10, n. 20, p. 23-54, Jul./Dez. 2013.

RYZEWSKI, Juliano. Não incidência sobre serviços de beneficiamento. 2014. Disponível em: $<$ http://www.domtotal.com/ colunas/detalhes.php?artId=410>. Acesso em: 29 jan. 2015.

SILVA, Antônio Soares da. Mineração e áreas de preservação 
permanentes (apps) em Santo Antônio de Pádua - RJ. Revista

Sociedade \& Natureza. Uberlândia: n. 2, maio/ago. 2011.

SILVA, João Paulo Souza. Impactos ambientais causados por mineração.

Revista Espaço da Sophia. Tomazina (PR): n 8, ano I, nov. 2007.

SILVA, José Afonso da. Fundamentos constitucionais da proteção ambiental. In: DAIBERT, Arlindo (org.) Direito ambiental comparado. Belo Horizonte: Editora Fórum, 2008.

SOUZA, Gisele et al. Degradação em área de preservação permanente por extração de areia no rio Turvo em Adelândia, Goiás. Trabalho de conclusão de curso (Pontifícia Universidade Católica de Goiás). Goiânia: 2004. Disponível em: < http://www2.ucg.br/nupenge/ pdf/DegradacaoemAPP.pdf $>$. Acesso em: 17 mar. 2015.

STEINER, Frederich Antunes, VASCONCELOS, Vitor Vieira. Delimitação e proteção das áreas de preservação permanente de chapadas: estudo de caso da mineração de areia em encostas no norte de Minas Gerais.

Revista Caminhos de Geografia. Uberlândia: v. 12, n. 40, p. 189 - 204, dez. 2011.

TERMINSKI, Bogumil. Applying the Concept of Human Security to Research on the Consequences of Mining Induced Displacement and Resettlement. Nov. 2012. Disponível em: $<$ SSRN: $<$ http://ssrn.com/ abstract $=2177747>$. Acesso em: 21 fev. 2015.

VALVERDE, Fernando Mendes. Agregados para construção civil. In: Departamento Nacional de Produção Mineral. Sumário Mineral Brasileiro de 2006. Brasília: 2006, p 37-42.

VALVERDE, Fernando Mendes; SINTONI, Ayrton. Perfil da mineração de matérias-primas para construção civil no Estado de São Paulo. In: Workshop recursos minerais não-metálicos para o estado de São Paulo, n. 1, 1994, São Paulo. Boletim de Resumos. São Paulo: Sociedade Brasileira de Geologia - Núcleo São Paulo, p. 31-34, 1994. 
XI UNIVERSO da mineração brasileira. Revista Minérios \& Minerales. São Paulo: v.18, n. 240, p. 6-17, jul. 1999.

Artigo recebido em: 24/03/2015 Aprovado para publicação em: 02/12/2015

Como citar: VIEIRA, Geraldo. REZENDE, Elcio Nacur. Mineração de areia e meio ambiente: é possível harmonizar? Revista do Direito Público. Londrina, v.10, n.3, p.181-212, set/dez.2015. DOI: 10.5433/1980-511X.2015v10n3p181. ISSN: $1980-511 X$. 